\title{
MALLEABILITY OF WORKING MEMORY THROUGH CHESS TRAINING IN SCHOOL CHILDREN
}

\author{
Ebenezer Joseph $^{1}$, Veena Easvaradoss ${ }^{2}$, T. Edwin Prabhakaran ${ }^{3}, \&$ Sweta Jain ${ }^{4}$ \\ ${ }^{I}$ Cognitive Science Research Initiative, Government of India; P\&T Audit Office (India) \\ ${ }^{2}$ Department of Psychology, Women's Christian College (India) \\ ${ }^{3}$ Department of Statistics, Loyola College (India) \\ ${ }^{4}$ Department of Psychology, Ethiraj College for Women (India)
}

\begin{abstract}
Working memory refers to a cognitive processing space where information is received, managed, transformed, and briefly stored. It is an operational process of transforming information for the execution of cognitive tasks in different and novel ways. Many class room activities require children to remember information and mentally manipulate it. While the effect of chess training on intelligence and academic performance has been examined, its impact on working memory needs to be studied. This study, funded by the Cognitive Science Research Initiative, Department of Science and Technology, Government of India, analyzed the effect of one-year chess training on the working memory of children. A pretest-posttest with control group design was used. The sample consisted of 88 children in the experimental group and 90 children in the control group. It was selected from children of both the genders studying in school (grades 3 to 9). The experimental group underwent weekly chess training for one year, while the control group was involved in extracurricular activities offered by the school such as cricket, hockey, football etc. Working memory was measured by two subtests of WISC-IV INDIA. The Digit Span Subtest involves recalling a list of numbers of increasing length presented orally in forward and in reverse order, and the Letter-Number Sequencing Subtest involves rearranging jumbled alphabets and numbers presented orally following a given rule. Both tasks require the child to receive and temporarily store information, manipulate it, and present it in a changed format. The children were trained using Winning Moves curriculum, audio-visual learning method, hands-on chess training and recording the games using score sheets, analyze their mistakes, thereby increasing their Meta-Analytical abilities. They were also trained in Opening theory, Checkmating techniques, End-game theory and Tactical principles. Analysis of Covariance revealed that the experimental group had significant gains in working memory compared to the control group. The present study ascertains a link between chess training and working memory. The transfer of chess training to the improvement of working memory could be attributed to the fact that while playing chess, children evaluate positions, visualize new positions in their mind, evaluate the pros and cons of each move, and decide moves based on the information stored in their mind. If working-memory's capacity could be expanded or made to function more efficiently, it could result in the improvement of executive functions as well as the scholastic performance of the child.
\end{abstract}

Keywords: Chess training, cognitive development, executive functions, school children, working memory.

\section{Introduction}

Working memory refers to a mental workspace that is involved in controlling, regulating, and actively maintaining relevant information to accomplish complex cognitive tasks (Miyake \& Shah, 1999). It is the small amount of information that can be held in mind and used in the execution of cognitive tasks, in contrast to long-term memory, which is the enormous amount of information saved in one's life. It has often been related to intelligence, information processing, executive function, comprehension, problem solving, and learning in people ranging from infancy to old age (Cowan, 2014).

Research evidence has linked performance on working memory tasks to vocabulary acquisition (Engel de Abreu, Gathercole, \& Martin, 2011); early academic success in reading (Gathercole \& Alloway, 2008; Stevenson, Bergwerff, Heisera, \& Resinga, 2014); mathematics (Arndt, Sahr, Opferman, Leutner, \& Fritz, 2013); and comprehension (Seigneuric, Ehrlich, Oakhill, \& Yuill, 2000). Furthermore, working memory ability measured when the child begins formal education strongly predicted success in reading, spelling and mathematics compared to IQ scores (Alloway \& Alloway, 2010) and short-term memory ability (Engle, Tuholski, Laughlin, \& Conway, 1999). 
A study carried out by Joseph, Easvaradoss, Kennedy, and Kezia (2016) assessed the impact of chess intervention on the general intelligence of children and analyzed the cognitive functions that contributed to the IQ gain. Significant increases were observed in IQ, and regression analysis indicated that nonverbal reasoning, language, and memory significantly contributed to the dependent variable IQ. Similar findings have been reported by Grabner, Stern, and Neubauer (2007). Since working memory is a better predictor of academic performance than IQ, it is imperative that research assesses the impact of programs that develop working memory. Rajah and Sundaram (2011) established that brief computer-aided intervention for improving neuropsychological functions such as attention and working memory has had a positive impact on the cognitive and academic skills of children who were average in academic performance.

However, research on the impact of chess training on working memory is not available. Chess is a game which involves working memory. While playing chess, the child mentally manipulates an enormous quantum of information, drawing on information stored in the long term memory and the data at hand. For example, the child concurrently uses blindfolded thinking (i.e. visualizing the positions of the chess game without looking at the board or picturing moves which had not occurred at all on the board), recalls and evaluates case studies of many typical positions while playing a chess game, connecting it to the game at hand. The outcomes of these mental operations are utilized to evaluate the positions, weigh various options, assess each potential move and make the optimum choice with the best outcome.

In the present study, it is hypothesized that systematic chess training would significantly increase working memory in children. The objective of the study was to assess the impact of a one - year chess training program with weekly sessions on the working memory of school going children.

\section{Methodology}

The research design used for the study was pretest-posttest with control group design (Edwards, 1985). The independent variable was the Chess training program and the dependent variable was the Working Memory of children. The sample comprised 178 children, 88 in the experimental group and 90 in the control group. The experimental group comprised 38 girls and 50 boys and the control group had 33 girls and 57 boys. The criteria for selecting the sample was children of both genders who are studying in schools, falling in the age range between 6 and 14 years (grade 3 to grade 9).

\subsection{Tools}

Assessment of Working Memory was carried out using the WISC-IV (Wechsler Intelligence Scale for Children-Fourth Edition, 2012). The test provided subtest and composite scores which represented intellectual functioning in specific cognitive domains and a composite score which represented general intellectual ability. To ensure accurate assessment, an Indian edition of WISC IV was used. Scores on the Digit Span subtest and the Letter-Number Sequencing subtest yielded the Working Memory Index.

Digit Span is a core Working Memory subtest composed of two parts: Digit Span Forward and Digit Span Backward. Digit Span Forward requires the child to repeat numbers in the same order as read aloud by the examiner, and Digit Span Backward requires the child to repeat the numbers in the reverse order of that presented by the examiner. This subtest is designed as a measure of auditory short term-memory, sequencing skills, attention and concentration. The Digit Span Forward task involves rote learning and memory, attention, encoding and auditory processing. Digit Span Backward involves working memory, transformation of information, mental manipulation and visuo-spatial imaging. The shift from the Digit Span Forward task to the Digit Span Backward task requires cognitive flexibility and mental alertness.

Letter-Number Sequencing is another core Working Memory subtest. A jumbled sequence of numbers and letters are read out by the examiner and the child recalls the numbers in ascending order and the letters in alphabetical order. This subtest involves sequencing, mental manipulation, attention, shortterm auditory memory, visuo-spatial imaging and processing speed.

\subsection{Chess training methodology}

The training methodology comprised Winning Moves Chess Learning Program (Joseph, 2008) Episodes 1-22, lectures with the demonstration board, on-the-board playing and training, chess exercise through workbooks (Chess school 1A, Chess school 2, and tactics) and working with chess software. Further children's games were mapped using chess base software and the brain patterns of the child were understood. They were taught the ideas behind chess openings and exposure to classical games were also given. The children participated in mock as well as regular tournaments. 


\section{Procedure}

Schools were identified and permission was obtained. Contracts were signed with the school to carry out the study. The children were randomly selected based on the inclusion criteria. Informed consent was obtained from the parents and the children. Random sampling within each school was used to form the experimental and control groups. Assessment was done for all students. Based on the IQ scores, children with identical IQ scores were paired, taking into consideration gender and age.

Clustering technique was used to form the training groups of 6 to 8 children. The chess training consisted of once a week chess classes conducted for one hour during school hours at the end of the day over one year. The children were given a standardized Winning Moves Chess Learning Program (Joseph, 2008) and played at tournaments also.

\section{Results}

The analysis was carried out using SPSS. Analysis of Covariance (ANCOVA) was used to compare the experimental and control groups on the dependent variable and to test the significance of difference between the means following chess training

Table 1. Descriptive statistics for working memory.

\begin{tabular}{|l|l|c|c|}
\hline \multirow{3}{*}{ Variable } & Assessment & $\begin{array}{c}\text { Experimental Group } \\
(\mathrm{N}=88)\end{array}$ & $\begin{array}{c}\text { Control Group } \\
\text { (N = 90) } \\
\end{array}$ \\
& & Mean/SD & Mean/SD \\
\hline Working & Pre & 90.92 & 90.1 \\
Memory & & $(15.201)$ & $(13.692)$ \\
\cline { 2 - 4 } & Post & 97.57 & 91.64 \\
& & $(14.585)$ & $(12.706)$ \\
\hline
\end{tabular}

Table 2. ANCOVA between intervention groups and control group on working memory at postintervention.

\begin{tabular}{|l|r|r|r|r|r|}
\hline \multicolumn{1}{|c|}{ Sources of variance } & \multicolumn{1}{c|}{$\begin{array}{c}\text { Sum of } \\
\text { Squares }\end{array}$} & \multicolumn{1}{c|}{ df } & \multicolumn{1}{c|}{$\begin{array}{c}\text { Mean } \\
\text { Square }\end{array}$} & \multicolumn{1}{c|}{ F } & \multicolumn{1}{c|}{ Sig. } \\
\hline Corrected Model & 14891.816 & 2 & 7445.908 & 66.673 & 0.000 \\
\hline Intercept & 7051.475 & 1 & 7051.475 & 63.141 & 0.000 \\
\hline Pre Working Memory & 13330.48 & 1 & 13330.48 & 119.365 & 0.000 \\
\hline Exp Con & 1310.777 & 1 & 1310.777 & 11.737 & $0.001 * *$ \\
\hline Error & 19543.74 & 175 & 111.678 & & \\
\hline Total & 1626478 & 178 & & & \\
\hline Corrected Total & 34435.55 & 177 & & & \\
\hline
\end{tabular}

Table 1 shows that the mean working memory increased in the experimental group from 90.92 to 97.57 following intervention, compared to the control group which showed an increase from 90.1 to 91.64. Table 2 indicates that there was a significant effect of intervention on Working Memory at postintervention $(\mathrm{p}<0.01)$.

Figure 1. Probability Density Function plot of pre-and postexperimental (left) and control (right) for working memory.
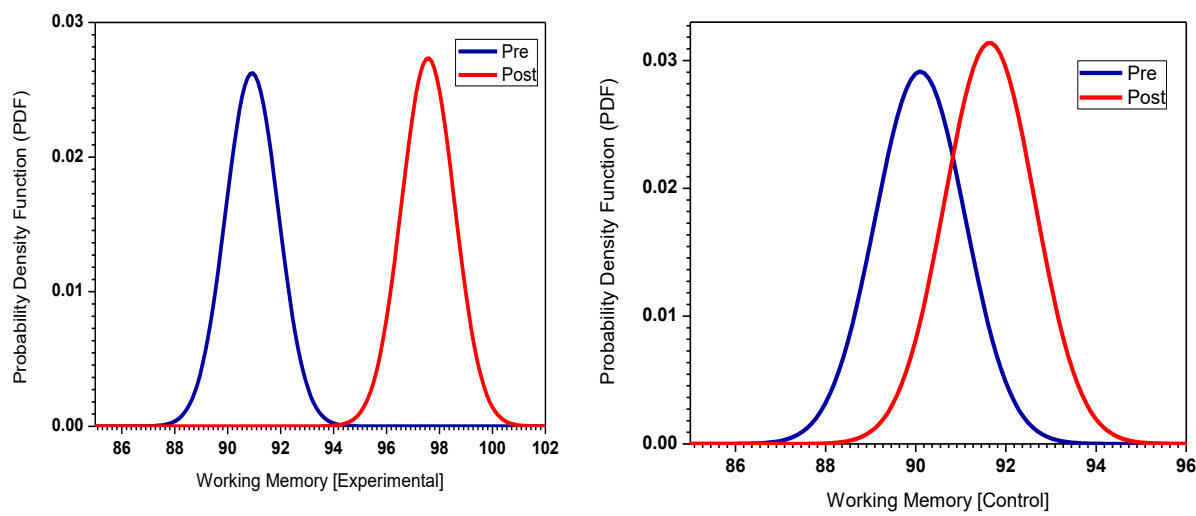
Figure 2. Cumulative Distribution Function plot of pre- and postexperimental (left) and control (right) for working memory.

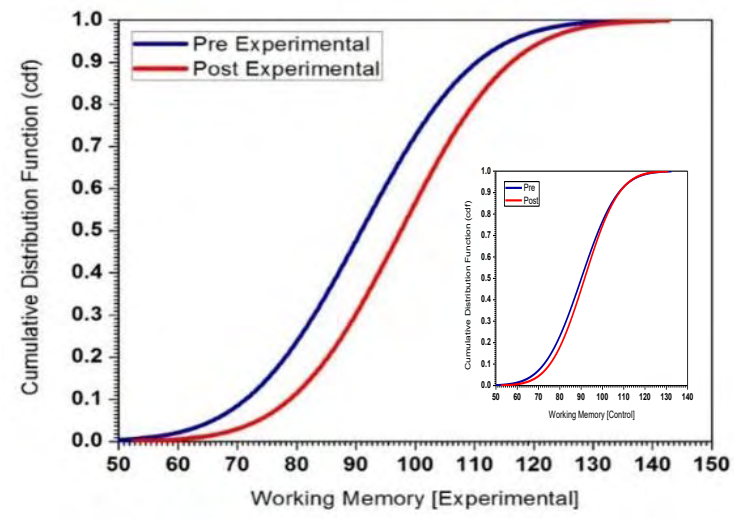

\subsection{Analysis of working memory-Gaussian normality curve}

The probability density function (PDF) plot in Figure 1 (left) clearly shows that pre- and postexperimental working memory distribution curves are distinctly separated and a higher mean is observed for postexperimental working memory. This indicates greater improvement in working memory in the children who underwent chess training (experimental group). However, the PDF plot in Figure 1 (right) clearly shows that pre- and postworking memory for control group are overlapped with each other, indicating not much improvement in working memory for control. The cumulative distribution function plots for pre- and postworking memory for experimental and control group are shown in Figure 2.

\section{Discussion}

The results clearly demonstrate that chess training has increased the working memory of the children who underwent the training when compared to the control group.

Children who received chess training appeared to have acquired the ability to juggle information while keeping in mind the already known information and the principles and rules of manipulation. In the present study, it was demonstrated that who children who had received chess training were able to transfer the ability to hold and manipulate information acquired during the training to tasks requiring similar abilities (namely the digit span and letter number sequencing tasks).

This effect has occurred after a year of chess intervention. It is probably the intensive and focused nature of the chess training which was individualized to the child's playing strength that resulted in the clear increase in scores. Further, a multisensory training approach was used ensuring that effective learning and development of chess playing skill was occurring.

Research has emphasized the encouraging effects resulting from working memory training. They have found a transfer effect on related tasks, such as tasks requiring following instructions, nonverbal reasoning and mathematical problem solving, and tasks involving attentional control (Brehmer, Westerberg, \& Backmann, 2012; Holmes, Gathercole, \& Dunning, 2009; Jaeggi, Buschkuehl, Jonides, $\&$ Perrig, 2008).

Melby-Lervåg and Hulme (2013), on the other hand, reported contradictory findings that working memory training does not generalize to other reasoning tasks. However the training programs are of short duration with a mean training duration of 12 hours across all the studies reviewed by them. Clearly a working memory training program of longer duration is required for transfer to be observed.

Many studies have established a link between working memory and academic achievement (Gathercole \& Pickering, 2000). In one study, working memory independently predicted the children's achievements in reading and to a lesser extent in mathematics, thereby indicating that working memory was common to the domains of reading and mathematics (Gathercole, Alloway, Willis, \& Adams, 2006). Furthermore, working memory tests (digits backwards and sentence repetition) appeared to be the best predictors of mathematical test scores and may represent a major cognitive defect in children with specific defects in mathematics(Rosselli, Matute, Pinto, \& Ardila, 2006).

\section{Implications}

It is evident from the present study that there is a relationship between chess training and working memory. When systematic chess training with proper curriculum is offered, one could expect a significant gain in the working memory which can lead to educational implications for both normal children and special 
children. Strengthening working-memory through chess intervention could optimize its functioning; the positive outcomes would be seen not only in scholastic functioning but on other cognitive-behavioral attributes as well leading to holistic psychological well-being in the child. The potential educational gains of interventions using working memory training are valuable and therefore should be explored. Impacting working memory through chess training is thus a significant goal for psychologists, educationists, chess coaches and cognitive scientists.

\section{References}

Alloway, T. P., \& Alloway, R. G. (2010). Investigating the predictive roles of working memory and IQ in academic attainment. Journal of Experimental Child Psychology, 106(1), 20-29.

Arndt, D., Sahr, K., Opferman, M., Leutner, D., \& Fritz, A. (2013). Core knowledge and working memory as prerequisites of early school mathematics. South African Journal of Childhood Education, 3(1), $1-20$.

Brehmer, Y., Westerberg, H., \& Backmann, L. (2012). Working memory training in younger and older adults: Training gains, transfer and maintenance. Frontiers in Human Neuroscience, 6(63), 1-7.

Cowan, N. (2014). Working memory underpins cognitive development, learning and education. Educational Psychology Review, 26(2), 197-223.

Edwards, A. L. (1985). Experimental designs in psychological research. New York, NY: Harper \& Row.

Engel de Abreu, P. M. J., Gathercole, S. E., \& Martin, R. (2011). Disentangling the relationship between working memory and language: The roles of short-term storage and cognitive control. Learning and Individual Differences, 21(5), 569-574.

Engle, R. W., Tuholski, S. W., Laughlin, J. E., \& Conway, A. R. A. (1999). Working memory, short-term memory and general fluid intelligence: A latent-variable approach. Journal of Experimental Psychology, General, 128(3), 309-331.

Gathercole, S. E., \& Alloway, T. P. (2008). Working memory and learning: A practical guide for teachers. London: Sage.

Gathercole, S. E., Alloway, T. P., Willis, C., \& Adams, A. M. (2006). Working memory in children with reading disabilities. Journal of Experimental Child Psychology, 93, 265-281.

Gathercole, S. E., \& Pickering, S. J. (2000). Working memory deficits in children with low achievements in the national curriculum at 7 years. British Journal of Educational Psychology, 70, 177-194.

Grabner, R. H., Stern, E., \& Neubauer, A. C. (2007). Individual differences in chess expertise: A psychometric investigation. Acta Psychologica, 124, 398-420. Retrieved from http://dx.doi.org/10.1016/j.actpsy.2006.07.08

Holmes, J., Gathercole, S. E., \& Dunning, K. (2009). Adaptive training leads to sustained enhancement of poor working memory in children. Developmental Science, 12, F1-F7.

Jaeggi, S. M., Buschkuehl, M., Jonides, J., \& Perrig, W. J. (2008). Improving fluid intelligence with training on working memory. Proceedings of the National Academy of Sciences of the USA, 105(19), 6829-6833.

Joseph, E. (2008). India Patent No. L-32958/2009.

Joseph, E., Easvaradoss, V., Kennedy, A., \& Kezia, E. J. (2016). Chess training improves cognition in children. GSTF Journal of Psychology, 2(2), 1-6. doi:10.5176/2345-7872_2.2_33

Melby-Lervåg, M., \& Hulme, C. (2013). Is working memory training effective? A meta-analytic review. Developmental Psychology, 49, 270-291.

Miyake, A., \& Shah, P. (1999). Models of working memory: Mechanisms of active maintenance and executive control. Cambridge: Cambridge University Press.

Rajah, A., \& Sundaram, K. R. (2011). Changes in intellectual and academic performance of children following computer-based training: Preliminary results. Indian Journal of Psychiatry, 53(3), 249-252.

Rosselli, M., Matute, E., Pinto, N., \& Ardila, A. (2006). Memory abilities in children with subtypes of dyscalculia. Developmental Neuropsychology, 30(3), 801-818.

Seigneuric, A., Ehrlich, M. F., Oakhill, J. V., \& Yuill, N. M. (2000). Working memory resources and children's reading comprehension. Reading and Writing, 13(1/2), 81-103.

Stevenson, C. E., Bergwerff, C. E., Heisera, W. J., \& Resinga, W. C. M. (2014). Working memory and dynamic measures of analogical reasoning as predictors of children's math and reading achievement. Infant and Child Development, 23(1), 51-66. 